\title{
Copper-oxide impregnated respiratory masks may significantly reduce the risk of SARS-CoV-2 cross- contamination
}

Gadi Borkow ( $\sim$ gadib@medcu.com )

MedCu Technologies https://orcid.org/0000-0001-6170-5344

Danny Lustiger

MedCu Technologies

Eyal Melamed

Rambam Health Care Campus

Vicki Herrera

University of Nebraska Medical Center

Daniel Ackerman

National Strategic Research Institute

St. Patrick Reid

University of Nebraska Medical Center

Joshua Santarpia

University of Nebraska Medical Center

Article

Keywords: copper-oxide, SARS-CoV-2, COVID-19, face masks

Posted Date: September 8th, 2020

DOl: https://doi.org/10.21203/rs.3.rs-60610/v1

License: (c) (i) This work is licensed under a Creative Commons Attribution 4.0 International License. Read Full License 


\section{Abstract}

The use of protective respiratory face masks has been adopted universally as an important measure in the fight against COVID-19. Masks become contaminated by symptomatic and asymptomatic SARS-CoV2 infected individuals and the virus can remain viable on the surface of the masks for several days. Although the regular respiratory face masks are single use disposable masks, these masks are being largely reused and not often discarded after use by the general population. Mask touching during use, reuse and disposal occurs frequently, and this can lead to increased risk of infection and further transmission.

N95s and regular surgical masks were produced in which the external layers were made with nonwoven fabric impregnated with copper-oxide microparticles. The masks reduced the infectious titers of SARSCoV-2 by more than $99.9 \%$ within 1 minute of contact, as determined by $\mathrm{TCID}_{50}$ assay and serial PCR assays. The use of masks capable of rendering the SARS-CoV-2 non-infectious within minutes, may significantly reduce the risk of viral transmission and infection.

\section{Main Text}

The current ongoing pandemic caused by the highly pathogenic novel human coronavirus ${ }^{1}$, named severe acute respiratory syndrome coronavirus 2 (SARS-CoV-2), has infected more than 20 million individuals and caused more than 700,000 deaths worldwide. While initially it is believed that the virus was transmitted to humans from bats via unknown intermediate hosts ${ }^{2}$, it is now clear that the virus is spreading from human to human ${ }^{2}$.

Unfortunately, despite drastic measures taken by almost all countries to stop transmission, the virus continues to spread throughout the globe. Among these measures, the use of protective respiratory masks has been adopted universally.

Human-to-human transmission of the virus leading to infection of the respiratory tract can occur via two main routes. The first is direct exposure to aerosol particles and droplets generated during coughing or sneezing by symptomatic patients, and from asymptomatic individuals even before the onset of symptoms ${ }^{3}$. Symptomatic patients can transmit the virus for as long as the symptoms last and even following clinical recovery ${ }^{4}$. No significant differences were found in viral burden between symptomatic and asymptomatic individuals ${ }^{5}$, and thus asymptomatic individuals may unknowingly contribute significantly to the spread of the virus.

The second is through indirect contact with virus contaminated surfaces ${ }^{6,7}$, as following sneezing and coughing, the virus containing saliva droplets can spread 1-2 $m$ and deposit on surfaces ${ }^{8}$. The virus can remain viable on surfaces between hours and days, depending on the inoculum shed and environmental conditions $^{9}$. While on plastic, stainless steel, and cardboard, the median half-life of survival for the SARSCoV-2 is $6.81,5.63$ and 3.46 hours, respectively, on metallic copper it is 0.77 hours; less than in the 
aerosols (1.09) ${ }^{9}$. Disturbingly, SARS-CoV-2 virus can be retrieved from the surface of regular masks even after 7 days of exposure of the mask to the virus ${ }^{10}$. It has already been demonstrated that face masks and respirators can become contaminated with viral pathogens following their prolonged use ${ }^{11-13}$, and that mask and face touching is a frequent habit ${ }^{14}$. Taken together, this can lead to increased risk of infection and further viral transmission.

The use of protective respiratory masks has been shown to reduce significantly the risk of becoming infected with the SARS-CoV- $2^{15}$. Similarly, this was demonstrated for SARS-CoV-1, in which frequent use of facial masks contributed substantially to the control of the SARS epidemic in Hong Kong ${ }^{16}$. A metaanalysis of randomized controlled trials also showed that surgical masks are as effective as N95 masks in reducing transmission of influenza-like diseases ${ }^{17}$.

Copper, and copper-oxide, have potent virucidal properties ${ }^{18}$, including against SARS-CoV- $2^{19}$. A platform technology that impregnates different textiles with copper-oxide microparticles was developed, endowing them with wide spectrum biocidal properties ${ }^{20,21}$. By using a nonwoven fabric, impregnated with the copper-oxide microparticles, as the external layers of a N95 respiratory mask, it was demonstrated that within 30 minutes of their exposure to the mask above $99.9 \%$ of Human Influenza A (H1N1) and Avian Influenza Virus (H9N2) virions that remain on the mask were rendered non-infectious ${ }^{22}$. The high capacity of the nonwoven fabric to neutralize 12 additional different pathogenic viruses was demonstrated in separate studies ${ }^{23,24}$.

In accordance with the above, we here report that N95s and regular surgical masks (Figs 1a and 1b), in which the external layers were made with the nonwoven fabric impregnated with the copper-oxide microparticles (Figs 1c and 1d), reduced infectious titers of SARS-CoV-2 within 1 minute by more than 3 logs (Fig 2). The capacity of copper to neutralize readily coronaviruses has been previously demonstrated ${ }^{25}$. It was shown that copper alloys, with a concentration of above $60 \%$ copper content, renders the circulating human coronavirus 229E (HuCoV-229E) non-infectious within minutes. Copper ions released from the copper alloys and the generation of reactive oxygen species (ROS) were shown to be involved in the inactivation of the viruses ${ }^{25}$. In the above described antiviral nonwoven fabrics, the active copper form is already in the oxidized (activated) form (copper-oxide). This is one very significant step closer to releasing the active copper ions that damage the viruses, and hence the rapid inactivation of the virions, as opposed to the slower inactivation observed with pure copper ${ }^{9}$.

The presence of an antiviral nonwoven fabric, in both the layer in contact with the face and in the external layer of the mask, significantly reduces the risk of cross contamination during mask handling and disposal. The internal layer is especially relevant regarding asymptomatic individuals, who unknowingly contaminate their masks. Following the mask removal, they may contaminate their hands or gloves, and then unintentionally contaminate other high touch surfaces, such as door handles and elevator buttons. These surfaces may be touched by unexposed individuals, who then can become infected. 
The copper-oxide impregnated nonwoven fabric has been safely used for years in adult diapers and antimicrobial wound dressings ${ }^{26,27}$, which have been cleared by the FDA and other regulatory bodies. Their safety in respiratory face masks was also demonstrated ${ }^{22}$. It was found that the amount of copper that eluted to the air from the masks during 5 hours under simulated breathing conditions was $~ 100,000$ fold lower than the respiratory copper permissible exposure limit (PEL) set by the USA Occupational Safety and Health Administration ("OSHA"). The lowest observed-adverse-effect levels ("LOAELs") for chronic copper inhalation exposure was determined to be $0.64 \mathrm{mg} / \mathrm{m}^{3}$. The copper levels eluted during simulated breathing test, from the copper containing masks, was $0.09 \mathrm{pg} / \mathrm{m}^{3}$. This is a tiny fraction $(1,000,000$ folds less) of the copper LOAEL. Importantly, the outer layers of the masks do not cause any skin sensitization or skin irritation as determined in experimental studies and following the extensive safe use of the copper-oxide wound dressings and diapers by thousands of individuals ${ }^{26,27}$.

In view of the ongoing COVID-19 pandemic, both professional health workers, first responders and the public in large, are widely using one-time-use disposable masks. However, these masks are being largely reused and not often discarded after use. This by itself possesses an increased risk of viral transmission. The capacity of the copper-oxide impregnated masks to render the coronavirus non-infectious within minutes on the contaminated masks, may significantly reduce the risk of viral transmission and infection in view of the reuse of masks, especially by the public in large.

\section{Declarations}

\section{Acknowledgements}

This study has been funded in whole or in part with Federal funds from the Department of Health and Human Services: Office of the Assistant Secretary for Preparedness and Response: COVID-19 Materials Science Research under Contract No. 75A50120C00109.

\section{Conflict of interests}

G.B, D.L and E.M were involved in the development of the antiviral mask technology. All other authors do not have a conflict of interests.

\section{References}

1 Zhu N, Zhang D, Wang W et al. A Novel Coronavirus from Patients with Pneumonia in China, 2019. N Engl J Med 2020;382:727-33.

2 Guo YR, Cao QD, Hong ZS et al. The origin, transmission and clinical therapies on coronavirus disease 2019 (COVID-19) outbreak - an update on the status. Mil Med Res 2020;7:11.

3 Rothe C, Schunk M, Sothmann P et al. Transmission of 2019-nCoV Infection from an Asymptomatic Contact in Germany. N Engl J Med 2020;382:970-1. 
4 Singhal T. A Review of Coronavirus Disease-2019 (COVID-19). Indian J Pediatr 2020;87:281-86.

5 Zou L, Ruan F, Huang M et al. SARS-CoV-2 Viral Load in Upper Respiratory Specimens of Infected Patients. N Engl J Med 2020;382:1177-9.

6 Ong SWX, Tan YK, Chia PY et al. Air, Surface Environmental, and Personal Protective Equipment Contamination by Severe Acute Respiratory Syndrome Coronavirus 2 (SARS-CoV-2) From a Symptomatic Patient. JAMA 2020;323:1610-2.

7 Ye G, Lin H, Chen L et al. Environmental contamination of the SARS-CoV-2 in healthcare promises: an urgent call for protection for healthcare workers. medRxiv 2020.

8 Cai J, Sun W, Huang J et al. Indirect Virus Transmission in Cluster of COVID-19 Cases, Wenzhou, China, 2020. Emerg Infect Dis 2020;26(6).

9 van DN, Bushmaker T, Morris DH et al. Aerosol and Surface Stability of SARS-CoV-2 as Compared with SARS-CoV-1. N Engl J Med 2020;382:1564-7.

10 Chin AWH, Chu JTS, Perera MRA et al. Stability of SARS-CoV-2 in different environmental conditions. Lancet 2020 April 2 (Epub ahead of print).

11 Phan LT, Sweeney D, Maita D et al. Respiratory viruses on personal protective equipment and bodies of healthcare workers. Infect Control Hosp Epidemiol 2019;40:1356-60.

12 Blachere FM, Lindsley WG, McMillen CM et al. Assessment of influenza virus exposure and recovery from contaminated surgical masks and N95 respirators. J Virol Methods 2018;260:98-106.

13 Chughtai AA, Stelzer-Braid S, Rawlinson W et al. Contamination by respiratory viruses on outer surface of medical masks used by hospital healthcare workers. BMC Infect Dis 2019;19: 491.

14 Kwok YL, Gralton J, McLaws ML. Face touching: a frequent habit that has implications for hand hygiene. Am J Infect Control 2015;43:112-4.

15 Leung NHL, Chu DKW, Shiu EYC et al. Respiratory virus shedding in exhaled breath and efficacy of face masks. Nat Med 2020;26:676-80.

16 Lau JT, Tsui H, Lau M, Yang X. SARS transmission, risk factors, and prevention in Hong Kong. Emerg Infect Dis 2004;10:587-92.

17 Long Y, Hu T, Liu L et al. Effectiveness of N95 respirators versus surgical masks against influenza: A systematic review and meta-analysis. J Evid Based Med 2020;13:93-101.

18 Borkow G. Using copper to fight microorganisms. Curr Chem Biol 2012;6:93-103. 
19 Behzadinasab S, Chin A, Hosseini M, Poon LLM, Ducker WA. A Surface Coating that Rapidly Inactivates SARS-CoV-2. ACS Appl Mater Interfaces 2020 July 3 (Epub ahead of print).

20 Borkow G, Gabbay J. Putting copper into action: copper-impregnated products with potent biocidal activities. FASEB J 2004;18:1728-30.

21 Borkow G, Gabbay J. Endowing textiles with permanent potent biocidal properties by impregnating them with copper oxide. JTATM 2006;5(1).

22 Borkow G, Zhou SS, Page T, Gabbay J. A novel anti-influenza copper oxide containing respiratory face mask. PLoS One 2010;5:e11295.

23 Borkow G, Sidwell RW, Smee DF et al. Neutralizing viruses in suspensions by copper oxide based filters. Antimicrob Agents Chemother 2007;51:2605-7.

24 Borkow G, Lara HH, Covington CY, Nyamathi A, Gabbay J. Deactivation of human immunodeficiency virus type 1 in medium by copper oxide-containing filters. Antimicrob Agents Chemother 2008;52:518-25.

25 Warnes SL, Little ZR, Keevil CW. Human Coronavirus 229E Remains Infectious on Common Touch Surface Materials. mBio 2015;6:e01697-15.

26 Borkow G, Okon-Levy N, Gabbay J. Copper oxide impregnated wound dressings: biocidal and safety studies. Wounds 2010;22:310-6.

27 Weinberg I, Lazary A, Jefidoff A et al. Safety of using diapers containing copper oxide in chronic care elderly patients. The Open Biology Journal 2013;6:54-9.

\section{Figures}



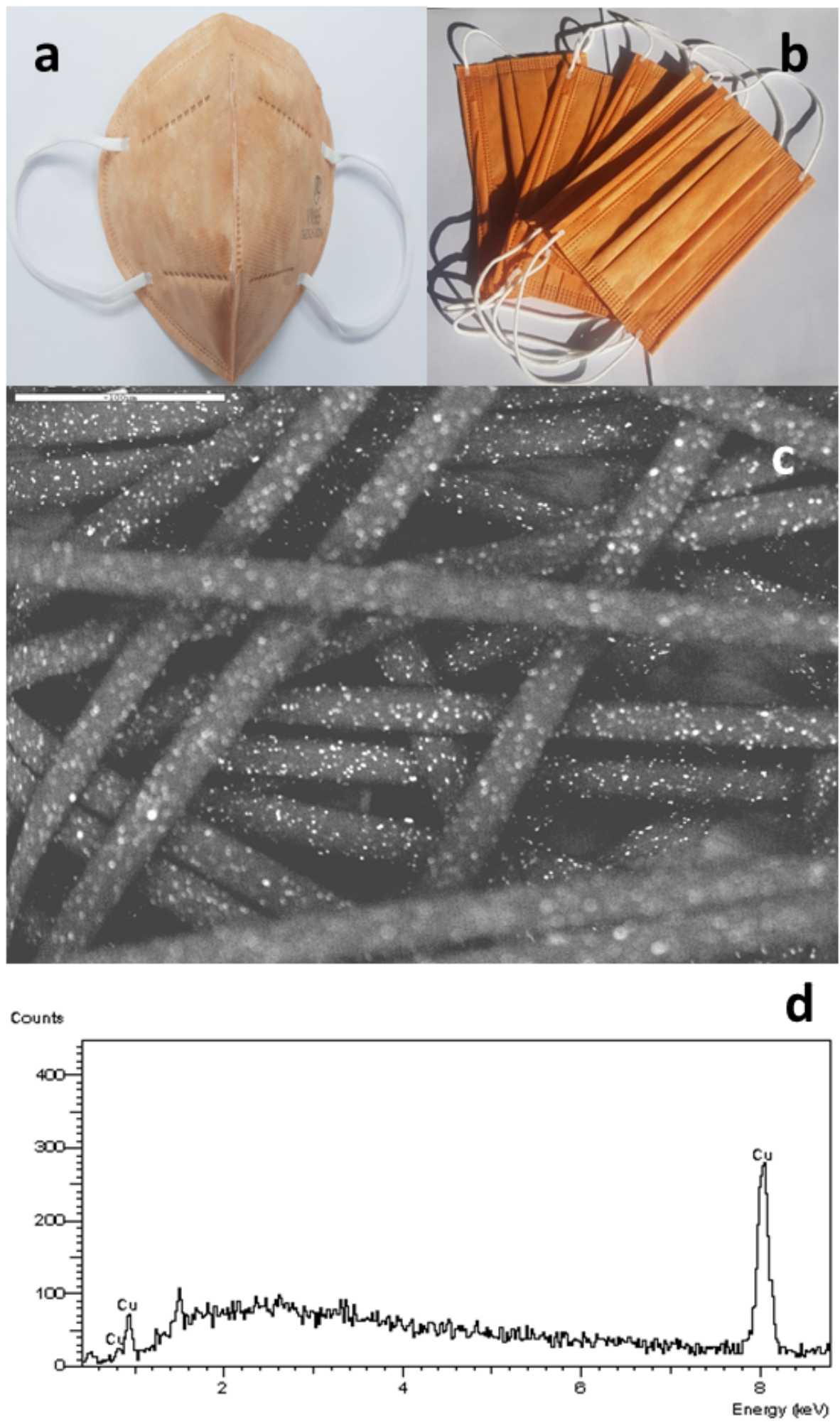

\section{Figure 1}

Surgical face masks impregnated with copper oxide microparticles. N95 (a) and surgical masks (b) external layers are made from polypropylene spunbond fabric impregnated with copper-oxide microparticles. The microparticles are the white dots seen by using scanning electronic microscope imaging (c), as determined by X-ray photoelectron spectrum analysis of the white dots (d). 
A. TCID50

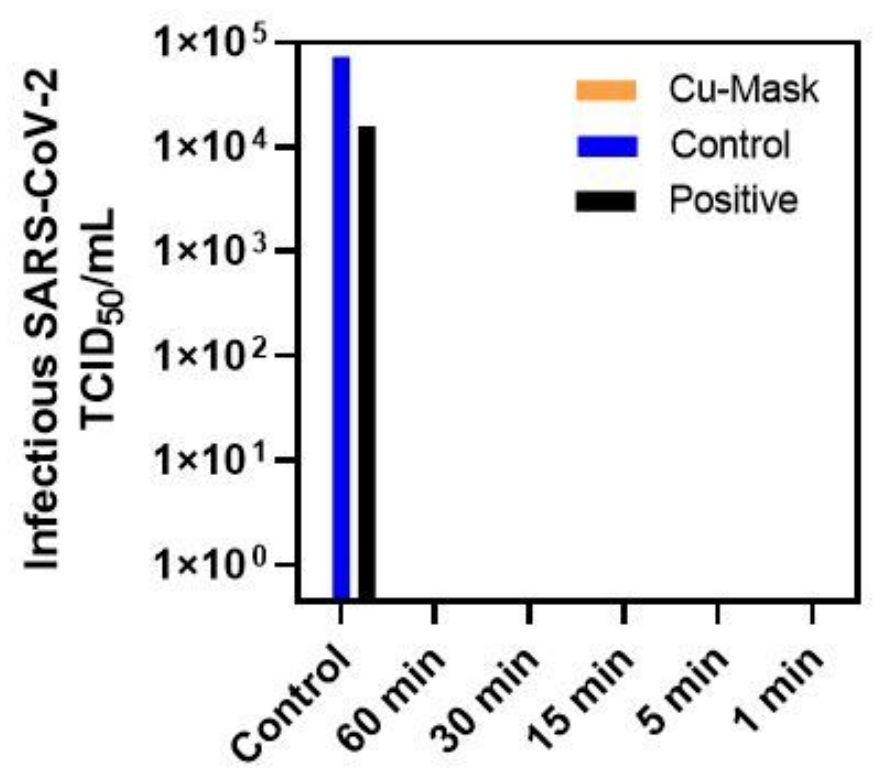

Exposure Time
B. Serial PCR

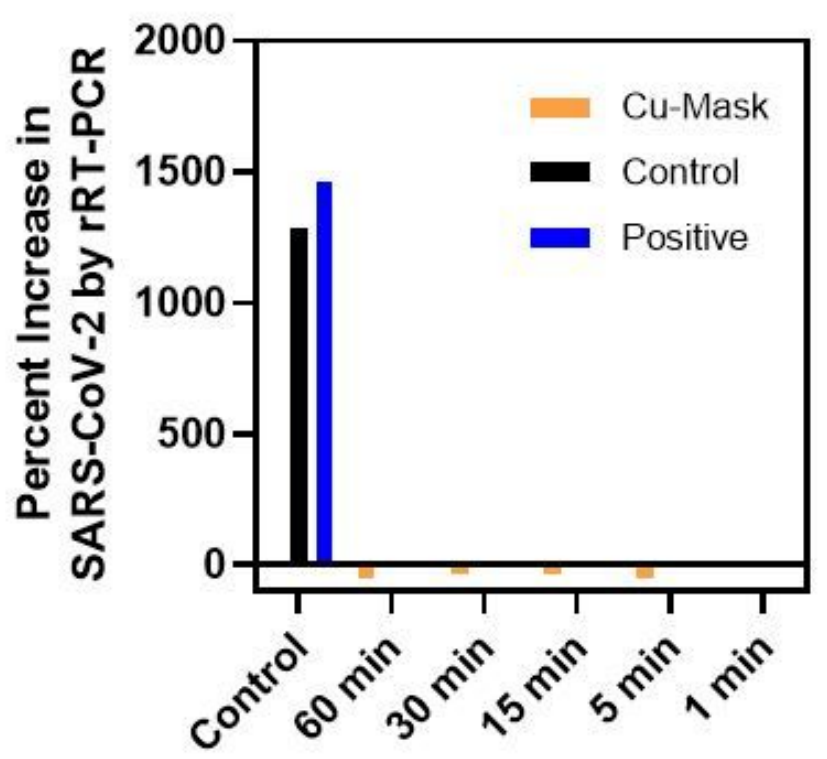

Exposure Time

Figure 2

Reduction of infectious titers of SARS-CoV-2 by copper oxide microparticle-impregnated masks (Cumask). Five coupons of the Cu-masks ( $\mathrm{MedCu}$ ) and one coupon of a regular surgical mask (Control) were inoculated with $100 \mu \mathrm{l}$ of $4.46 \mathrm{e} 5 \mathrm{TCID} 50 / \mathrm{mL}$ of SARS-CoV-2. The coupons were recovered after $1,5,15$, 30 and 60 minutes. Recovery of the virions was done by vortexing the sample for 1 minute in $10 \mathrm{ml}$ of sterile buffer phosphate (PBS). As a positive control (Positive), $100 \mu \mathrm{l}$ of virus were added into $10 \mathrm{ml}$ of PBS. PBS alone was used as negative control. Fluid recovered from coupons was inoculated into Vero E6 cells for TCID50 assay (A) and serial PCR (B). Immediately after inoculation and after 3 days $140 \mu \mathrm{L}$ of supernatant was withdrawn and viral RNA was extracted using Qiagen Viral RNA Mini Kit. Following RNA extraction, rRT-PCR on E gene of SARS-CoV-2 was performed. No evidence of replication was observed in any of 5 time points from the MedCu masks in TCID50 assays $\left({ }^{*}\right)$, and in serial PCR a percent decrease in viral RNA $(-39 \cdot 6+/-17 \cdot 2 \%)$ was observed, confirming inactivation of all virion after contact with the MedCu mask for times between 1 and 60 minutes. Both TCID50 and serial PCR confirmed viral replication in the control mask and positive control. 